\title{
Real-world outcomes of rivaroxaban treatment in elderly Japanese patients with nonvalvular atrial fibrillation
}

\author{
Takanari Kitazono $^{1} \cdot$ Takanori Ikeda $^{2} \cdot$ Satoshi Ogawa ${ }^{3} \cdot$ Jyoji Nakagawara $^{4,5} \cdot$ Kazuo Minematsu $^{5,6} \cdot$ \\ Susumu Miyamoto ${ }^{7} \cdot$ Yuji Murakawa $^{8} \cdot$ Mary Cavaliere $^{9} \cdot$ Yasuhiro Hayashi $^{9} \cdot$ Yoko Kidani $^{9} \cdot$ Yutaka Okayama $^{10}$. \\ Toshiyuki Sunaya $^{11}$. Shoichiro Sato ${ }^{10} \cdot$ Satoshi Yamanaka ${ }^{9}$
}

Received: 29 March 2019 / Accepted: 23 August 2019 / Published online: 6 September 2019

(c) The Author(s) 2019

\begin{abstract}
Direct oral anticoagulants (DOACs), such as rivaroxaban, reduce the risk of stroke and systemic embolism in patients with nonvalvular atrial fibrillation (NVAF). However, it is still unclear whether the stroke reduction benefit outweighs the bleeding risk in elderly Japanese patients with NVAF. The Xarelto Post-Authorization Safety and Effectiveness Study in Japanese Patients with Atrial Fibrillation (XAPASS) was a real-world, prospective observational, post-marketing surveillance study on the safety and effectiveness of rivaroxaban in Japanese clinical practice. This sub-analysis evaluated the clinical outcomes of elderly patients aged $\geq 75$ years. At the 1 -year follow-up, there were 4,685 (48.91\%) and 4,893 (51.09\%) patients aged $\geq 75$ and $<75$ years, respectively. Safety and effectiveness outcomes were compared between patients aged $\geq 75$ years and those aged $<75$ years, and among 3 elderly sub-populations (age ranges: $75-79,80-84$, and $\geq 85$ years). Patients aged $\geq 75$ years had higher rates of major bleeding [ 2.22 vs. 1.35 events per 100 patient-years, hazard ratio (HR) $1.63,95 \%$ confidence interval (CI) 1.17-2.28] and composite of stroke (ischemic or hemorrhagic)/non-central nervous system (non-CNS) systemic embolism (SE)/myocardial infarction (MI) (2.41 vs. 1.21 events per 100 patient-years, HR 1.97, 95\% CI 1.40-2.77) compared to patients aged $<75$ years. Intracranial hemorrhage rates were $<1$ event per 100 patient-years in both groups $(0.85$ vs. 0.59 events per 100 patient-years, HR 1.43, 95\% CI 0.85-2.40). Kaplan-Meier curves of major bleeding and stroke/non-CNS SE/MI showed that no significant differences of cumulative event rates were identified among the 3 elderly sub-populations. Stepwise Cox regression analyses revealed that creatinine clearance $(\mathrm{CrCl})(<50 \mathrm{~mL} / \mathrm{min})$, hepatic impairment, and hypertension were specific predictors for major bleeding and no specific predictors were found for stroke/non-CNS SE/MI in patients aged $\geq 75$ years. In conclusion, safety and effectiveness event rates were higher in patients aged $\geq 75$ years compared with those aged $<75$ years, yet, no distinct differences were observed among the 3 elderly sub-populations.
\end{abstract}

Keywords Rivaroxaban $\cdot$ Atrial fibrillation $\cdot$ Anticoagulant $\cdot$ Elderly $\cdot$ Benefit-risk balance

\section{Introduction}

Atrial fibrillation (AF) is a growing epidemic and an important public health problem as the world population ages. In particular, AF patients in an elderly population are of considerable clinical interest, since they are at a high risk for not only ischemic stroke [1], but also bleeding that derives

Electronic supplementary material The online version of this article (https://doi.org/10.1007/s00380-019-01487-x) contains supplementary material, which is available to authorized users.

Takanari Kitazono

kitazono@intmed2.med.kyushu-u.ac.jp

Extended author information available on the last page of the article from multiple complicating factors, including comorbidities, polypharmacotherapy, cognitive deficits, and falling [2,3]. Due to those complexities, practicing physicians often must perform a delicate balance and proper decision making. In addition, the decision making for such an elderly patient population is a challenge due to the limited availability of clinical and real-world data.

Rivaroxaban is a direct factor Xa inhibitor; the safety and efficacy of rivaroxaban were examined and compared with warfarin as a standard treatment. In the ROCKET AF study, which included 14,264 patients with nonvalvular atrial fibrillation (NVAF) worldwide, rivaroxaban demonstrated non-inferiority to warfarin for the prevention of stroke or systemic embolism [4]. In a similar study, the J-ROCKET 
AF study, focusing on Japanese patients and Japan-specific dosage, rivaroxaban demonstrated non-inferiority to warfarin for the principal safety outcome of major and non-major clinically relevant bleeding in patients with NVAF [5]. As the patient backgrounds, including age, may be less diverse in clinical trial settings, real-world studies will become more and more important in this regard [6].

Japan is a front runner of super-aged societies [7] with the highest average life expectancy in the world at 84 years (87 years for women and 80 years for men) [8,9]. The prevalence of AF has been increasing in Japan as the population ages, as in Western countries, and the rate is projected to be $0.91 \%$ in 2030 and $1.09 \%$ in 2050 [10]. Therefore, there is a growing interest in the real-world evidence of direct oral anticoagulant treatment for elderly patients with NVAF.

As a real-world, post-authorization, prospective, singlearm, non-interventional cohort study, we performed the XAPASS that evaluated the safety and effectiveness of rivaroxaban in Japanese patients with NVAF [11]. The results revealed low incidence rates of bleeding and thromboembolic events, suggesting that rivaroxaban is safe and effective for stroke prevention in daily clinical practice [12]. The current study is a sub-analysis of the XAPASS focusing on elderly patients aged $\geq 75$ years. The safety and effectiveness outcomes and possible predictive factors of major bleeding and thromboembolic events were evaluated. The sub-analysis provides additional information that may help facilitate treatment decisions for elderly patients aged $\geq 75$ years in Japan.

\section{Materials and methods}

\section{Study design}

The XAPASS (Clinicaltrials.gov: NCT01582737) was undertaken as a real-world, prospective, open-label, singlearm, observational, post-authorization cohort study conducted in Japan. The study design was described previously [11]. Briefly, the standard observation period for each patient is 2 years; data are collected at 6 months, 1 year, and 2 years after the initiation of rivaroxaban treatment. After the completion of the standard observation period, follow-up investigations are being conducted for a maximum for 5 years. The study was approved by the Ministry of Health, Labour, and Welfare in Japan and was carried out in accordance with the standards for Good Post-marketing Study Practice (GPSP) provided by this ministry. Individual consent and institutional approval of ethical standards in accordance with the Declaration of Helsinki are not necessary in activities and research for the safety surveillance, such as signal detection and prospective cohort studies.

\section{Patients}

A total of 11,308 Japanese patients with NVAF were enrolled in the XAPASS between April 2012 and June 2014. The current sub-analysis included 9,578 patients who had completed a 1-year follow-up as of September 2017.

\section{Treatment}

Patients received oral rivaroxaban at a dosage of either $15 \mathrm{mg}$ once daily (od) or $10 \mathrm{mg}$ od, prescribed at the discretion of the treating physicians. These dosages are approved in Japan for patients with $\mathrm{CrCl} \geq 50$ and $<50 \mathrm{~mL} / \mathrm{min}$, respectively.

\section{Risk scores}

The following scores, as determined at baseline to assess stroke risk, were compared in patients aged $\geq 75$ years and patients aged $<75$ years: $\mathrm{CHADS}_{2}$ (congestive heart failure, hypertension, age, diabetes mellitus, stroke) [13] and $\mathrm{CHA}_{2} \mathrm{DS}_{2}$-VASc (congestive heart failure, hypertension, age $\geq 75$ years, diabetes mellitus, stroke, vascular disease, age 65-74 years, sex category) [14]. A modified HAS-BLED score, also determined at baseline to assess bleeding risk, included the following factors: hypertension, abnormal liver/renal function, stroke history, bleeding predisposition, elderly, and drug/alcohol use. The labile international normalized ratio was excluded from the score $[12,15]$.

\section{Study outcomes}

The primary safety outcome was any bleeding. Major bleeding and intracranial haemorrhage (ICH) were recorded as the components. Major bleeding was defined according to the International Society of Thrombosis and Haemostasis criteria [16], whereas non-major bleeding was defined as any bleeding that did not meet these criteria. The primary effectiveness outcome was a composite of stroke (hemorrhagic or ischemic), non-central nervous system (non-CNS) $\mathrm{SE}$, and myocardial infarction (MI). All the outcomes were defined previously $[11,12]$. Stroke and ischemic stroke were recorded as individual outcomes. Transient ischemic attack (TIA) was not included in the stroke endpoint.

\section{Statistical analysis}

Survival curves were estimated by the Kaplan-Meier method. Cox regression analysis was performed to estimate hazard ratios of outcomes, which were compared between patients aged $\geq 75$ and $<75$ years, and among the 3 elderly 
sub-populations (age ranges: $75-79,80-84$, and $\geq 85$ years). $P$ values were calculated using the log-rank test. A competing risk analysis was performed using the Fine and Gray's proportional subhazards model [17] to compare the cumulative incidence function of major bleeding and stroke/nonCNS SE/MI events among the 3 elderly sub-populations with 'death before event occurrence' as the competing risk. Predictive factors for major bleeding and stroke/non-CNS SE/MI events in patients aged $\geq 75$ and $<75$ years were estimated by multivariable and stepwise analyses using the Cox proportional hazards model with a significance level of $5 \%$. The following variables at the study enrollment were included: female gender, body weight, $\mathrm{CrCl}$, initial dose, hypertension, diabetes mellitus, congestive heart failure, prior ischemic stroke/TIA, vascular disease, hepatic dysfunction, and oral antiplatelet use. $P<0.05$ was considered significant for the analysis. All statistical analyses were performed using SAS version 9.2 or higher (SAS Institute Inc., Cary, NC).

\section{Results}

\section{Patients}

Baseline characteristics are shown in Table 1. Of the 9,578 patients who completed the 1-year follow-up, 4,685 (48.91\%) patients were aged $\geq 75$ years. These patients were more likely to be female than patients aged $<75$ years $(47.51 \%$ vs. $29.25 \%)$ and had a lower body weight (mean: $56.80 \pm 11.83 \mathrm{~kg}$, vs. $65.75 \pm 12.73 \mathrm{~kg}$ ). Patients aged $\geq 75$ years had higher rates of $\mathrm{CrCl}<50 \mathrm{~mL} / \mathrm{min}$ $(41.86 \%$ vs. $6.58 \%)$, and higher rates of the following comorbidities: hypertension $(78.61 \%$ vs. $71.45 \%)$, prior ischemic stroke/TIA ( $27.85 \%$ vs. $17.33 \%$ ), and congestive heart failure (29.28\% vs. $20.56 \%$ ). In accordance with these higher comorbidity rates, patients aged $\geq 75$ years had higher $\mathrm{CHADS}_{2}, \mathrm{CHA}_{2} \mathrm{DS}_{2}$-VASc, and modified HAS-BLED scores (mean: $2.9 \pm 1.2$ vs. $1.5 \pm 1.1,4.4 \pm 1.3$ vs. $2.5 \pm 1.4$, and $1.9 \pm 0.9$ vs. $1.2 \pm 0.9$, respectively).

\section{Safety outcomes}

Patients aged $\geq 75$ years had higher rates of any bleeding (8.58 vs. 6.74 events per 100 patient-years, HR 1.26, 95\% CI 1.07-1.48), major bleeding (2.22 vs. 1.35 events per 100 patient-years, HR 1.63, 95\% CI 1.17-2.28), and fatal bleeding ( 0.28 vs. 0.09 events per 100 patient-years, HR 2.99, 95\% CI 0.95-9.38) compared to patients aged $<75$ years old (Table 2). ICH rates were $<1 \%$ in both age groups $(0.85$ vs. 0.59 events per 100 patient-years, HR $1.43,95 \% \mathrm{CI}$ $0.85-2.40$ ). In both patients aged $\geq 75$ and $<75$ years stratified by $\mathrm{CHADS}_{2}$ score, incidence rates of major bleeding
Table 1 Baseline patient characteristics

\begin{tabular}{|c|c|c|}
\hline & $<75$ years & $\geq 75$ years \\
\hline Characteristic & $(N=4,893)$ & $(N=4,685)$ \\
\hline Age, years & $65.7 \pm 7.4$ & $80.9 \pm 4.6$ \\
\hline Female sex & $1,431(29.25)$ & $2,226(47.51)$ \\
\hline Body weight, $\mathrm{kg}$ & $65.75 \pm 12.73$ & $56.80 \pm 11.83$ \\
\hline \multicolumn{3}{|l|}{ Body weight, $\operatorname{kg}[n(\%)]$} \\
\hline$\leq 50$ & $473(9.67)$ & $1392(29.71)$ \\
\hline$>50$ & $4,076(83.30)$ & $2,952(63.01)$ \\
\hline Unknown & $344(7.03)$ & $341(7.28)$ \\
\hline BMI, $\mathrm{kg} / \mathrm{m}^{2}$ & $24.51 \pm 3.98$ & $23.27 \pm 4.07$ \\
\hline $\mathrm{CrCl}, \mathrm{mL} / \mathrm{min}$ & $81.4 \pm 31.3$ & $53.5 \pm 18.6$ \\
\hline \multicolumn{3}{|l|}{$\mathrm{CrCl}, \mathrm{mL} / \min [n(\%)]$} \\
\hline$<50$ & $322(6.58)$ & $1,961(41.86)$ \\
\hline$\geq 50$ & $4,173(85.29)$ & $2,348(50.12)$ \\
\hline Unknown & $398(8.13)$ & $376(8.03)$ \\
\hline $\mathrm{CHADS}_{2}$ score, mean $\pm \mathrm{SD}$ & $1.5 \pm 1.1$ & $2.9 \pm 1.2$ \\
\hline \multicolumn{3}{|l|}{ Score, $n(\%)$} \\
\hline 0 & $842(17.21)$ & 0 \\
\hline 1 & $1,886(38.54)$ & $447(9.54)$ \\
\hline 2 & $1,216(24.85)$ & $1,687(36.01)$ \\
\hline 3 & $677(13.84)$ & $1,199(25.59)$ \\
\hline 4 & $231(4.72)$ & 875 (18.68) \\
\hline 5 & $41(0.84)$ & $387(8.26)$ \\
\hline 6 & 0 & $90(1.92)$ \\
\hline 25 th percentile & 1 & 2 \\
\hline Median & 1 & 3 \\
\hline 75th percentile & 2 & 4 \\
\hline $\mathrm{CHA}_{2} \mathrm{DS}_{2}$-VASc score & $2.5 \pm 1.4$ & $4.4 \pm 1.3$ \\
\hline \multicolumn{3}{|l|}{ Score } \\
\hline 0 & $258(5.27)$ & 0 \\
\hline 1 & $908(18.56)$ & 0 \\
\hline 2 & $1,405(28.71)$ & $228(4.87)$ \\
\hline 3 & $1,238(25.30)$ & $1,008(21.52)$ \\
\hline 4 & $691(14.12)$ & $1,467(31.31)$ \\
\hline 5 & $302(6.17)$ & $1,077(22.99)$ \\
\hline 6 & $80(1.63)$ & $620(13.23)$ \\
\hline 7 & $11(0.22)$ & $239(5.10)$ \\
\hline 8 & 0 & $44(0.94)$ \\
\hline 9 & 0 & $2(0.04)$ \\
\hline 25 th percentile & 2 & 3 \\
\hline Median & 2 & 4 \\
\hline 75th percentile & 3 & 5 \\
\hline Modified HAS-BLED score* & $1.2 \pm 0.9$ & $1.9 \pm 0.9$ \\
\hline \multicolumn{3}{|l|}{ Score } \\
\hline 0 & $1,211(24.75)$ & 0 \\
\hline 1 & $2,128(43.49)$ & $1,813(38.70)$ \\
\hline 2 & $1,148(23.46)$ & $1,860(39.70)$ \\
\hline 3 & $333(6.81)$ & $818(17.46)$ \\
\hline 4 & $65(1.33)$ & $173(3.69)$ \\
\hline 5 & $6(0.12)$ & $20(0.43)$ \\
\hline 6 & 0 & $1(0.02)$ \\
\hline
\end{tabular}


Table 1 (continued)

\begin{tabular}{lll}
\hline & $<75$ years & $\geq 75$ years \\
\hline 7 & 0 & 0 \\
8 & 0 & 0 \\
25th percentile & 1 & 1 \\
Median & 1 & 2 \\
75th percentile & 2 & 2 \\
Baseline comorbidities & & \\
Hypertension & $3,496(71.45)$ & $3,683(78.61)$ \\
Diabetes mellitus & $1,182(24.16)$ & $957(20.43)$ \\
Prior ischemic stroke/TIA & $848(17.33)$ & $1,305(27.85)$ \\
Congestive heart failure & $1,006(20.56)$ & $1,372(29.28)$ \\
Hepatic dysfunction & $360(7.36)$ & $228(4.87)$ \\
Type of AF & & \\
Paroxysmal & $1,728(35.32)$ & $1,493(31.87)$ \\
Persistent & $1,724(35.23)$ & $1,702(36.33)$ \\
Permanent & $1,192(24.36)$ & $1,151(24.57)$ \\
Other & $10(0.20)$ & $12(0.26)$ \\
Unknown & $239(4.88)$ & $327(6.98)$ \\
\hline
\end{tabular}

Data are presented as $n(\%)$ or mean \pm standard deviation

$A F$ atrial fibrillation, $B M I$ body mass index, $\mathrm{CrCl}$ creatinine clearance, INR international normalized ratio, TIA transient ischemic attack

*Maximum score is 8 because of the exclusion of the factor "labile INR" from the HAS-BLED score trended higher with higher $\mathrm{CHADS}_{2}$ score (Fig. 1a). Cox regression analysis showed that there was no significant increased rates in major bleeding (HR $1.45,95 \% \mathrm{CI}$ 0.89-2.37 for 80-84 years vs. 75-79 years and HR 1.60, 95\% CI 0.93-2.76 for $\geq 85$ years vs. $75-79$ years) (Fig. 2a). We note that incidence rate of death was $1.71,4.79$, and 8.47 events per 100 patient-years for patients aged 75-79, $80-84$, and $\geq 85$ years, respectively (Supplementary Fig. 1). A competing risk analysis showed that no significant difference in the incidence rates of major bleeding among the three elderly age groups even with adjustment for mortality was observed (Supplementary Table 1).

\section{Effectiveness outcomes}

Patients aged $\geq 75$ years had higher rates of the composite endpoint stroke/non-CNS SE/MI compared with those aged $<75$ years ( 2.41 vs. 1.21 events per 100 patient-years, HR 1.97, 95\% CI 1.40-2.77; Table 2). They also had higher rates of the individual endpoints of stroke (2.07 vs. 1.14 events per 100 patient-years, HR 1.80, 95\% CI 1.26-2.57) and ischemic stroke ( 1.55 vs. 0.73 events per 100 patientyears, HR 2.09, 95\% CI 1.35-3.22). In both patients aged $\geq 75$ and $<75$ years stratified by $\mathrm{CHADS}_{2}$ score, there was a similar tendency for incidence rates of stroke/ non-CNS SE/MI to increase as the rates of major bleeding increased (Fig. 1b). Cox regression analysis showed that

Table 2 Safety and effectiveness outcomes

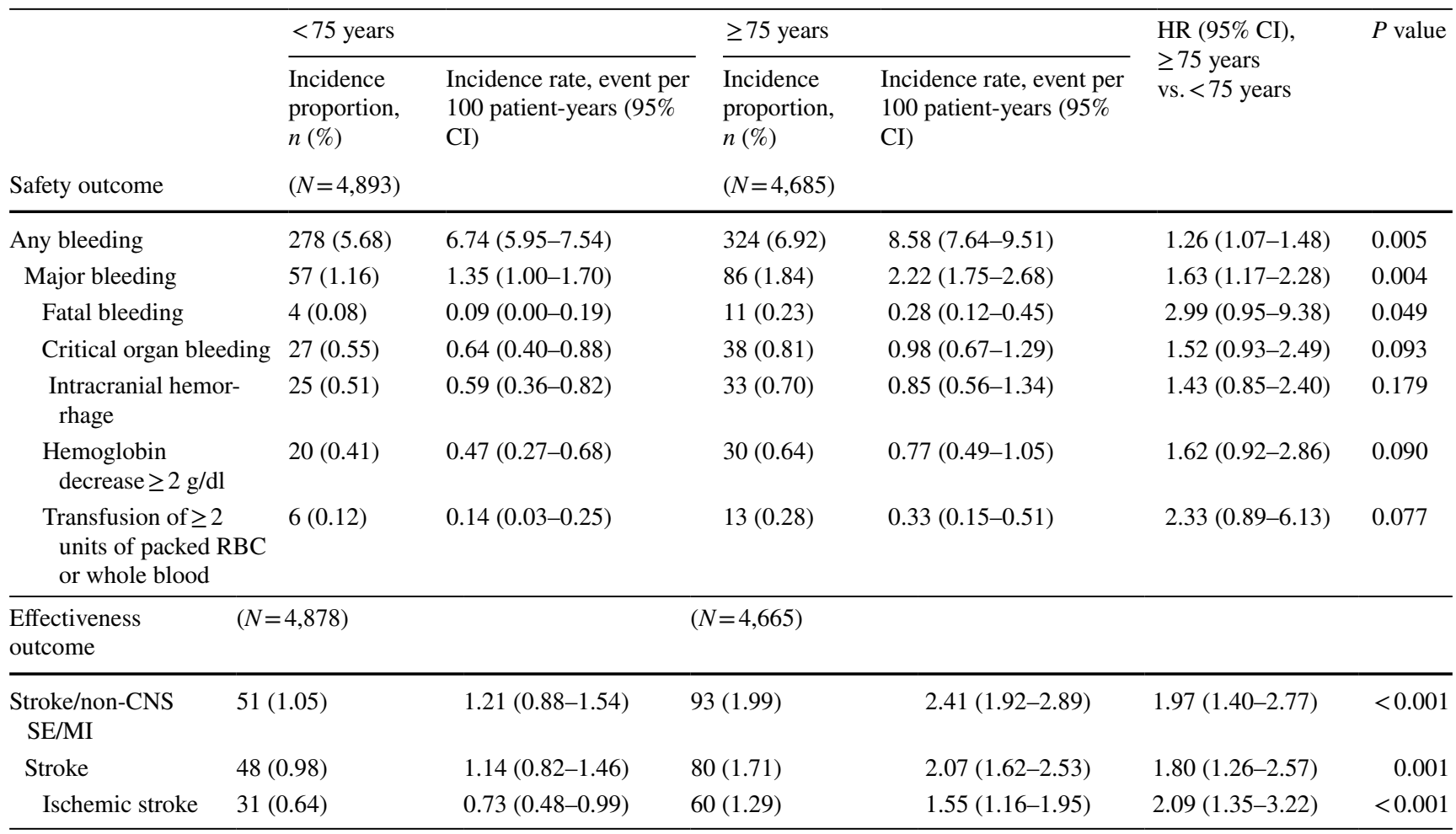



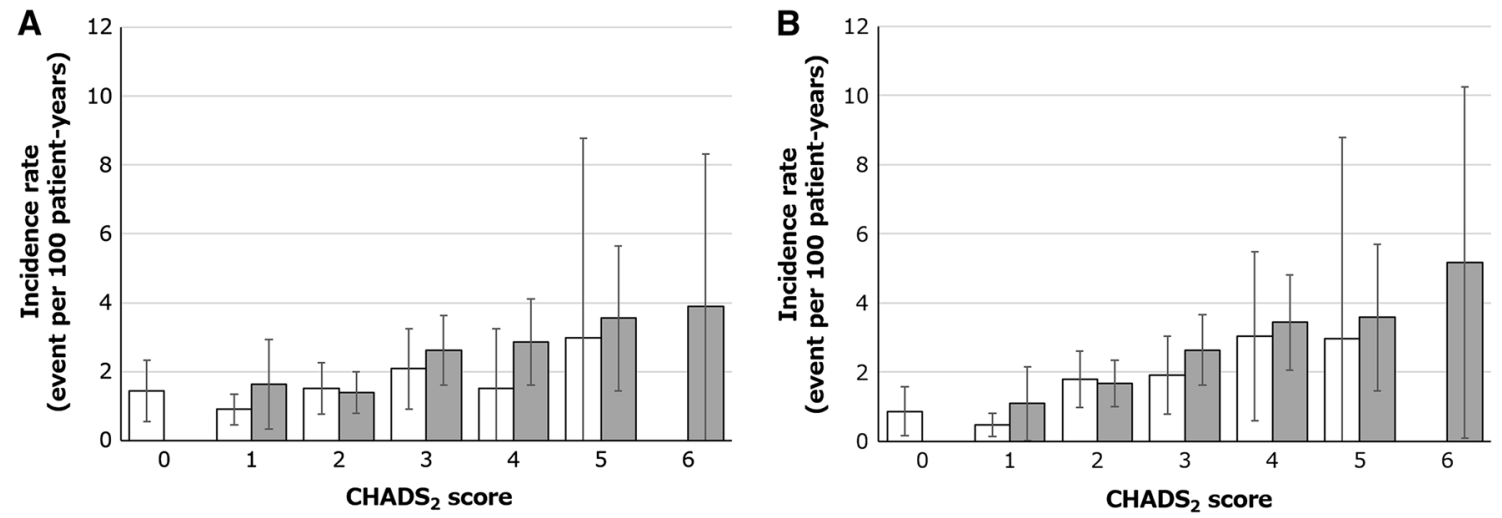

Fig. 1 Incidence rates of a major bleeding and $\mathbf{b}$ stroke/non-CNS SE/MI stratified by baseline $\mathrm{CHADS}_{2}$ score. Gray and white bar indicate the rates for patients aged $\geq 75$ and $<75$ years, respectively. Error bars indicate the corresponding $95 \%$ confidence interval

A

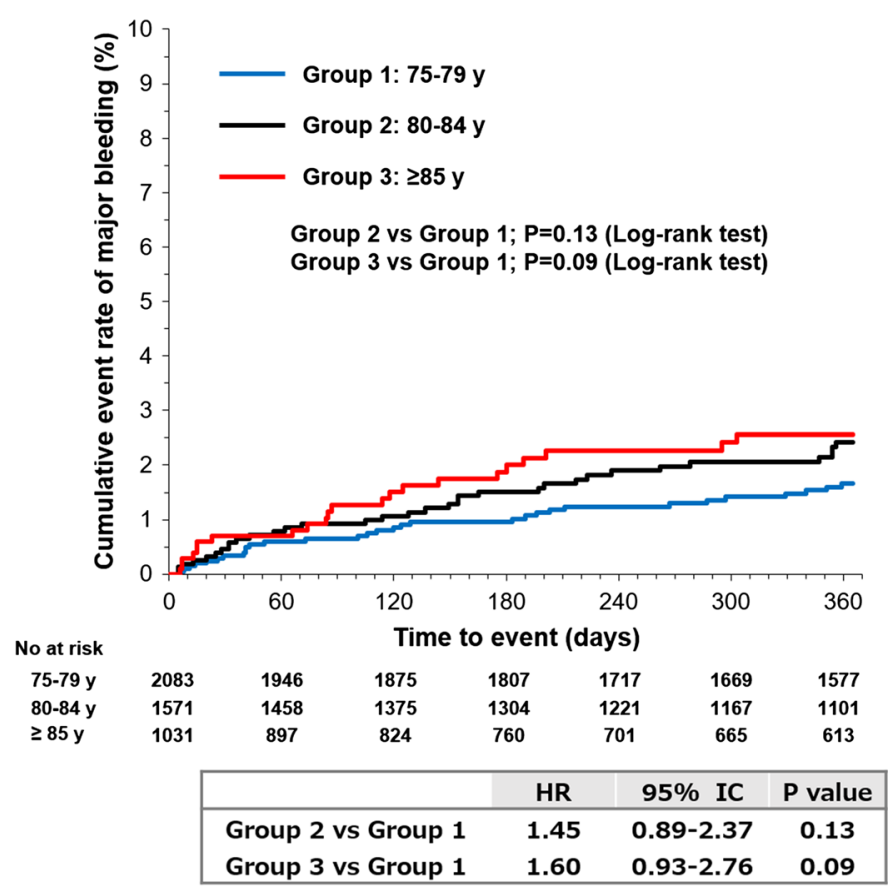

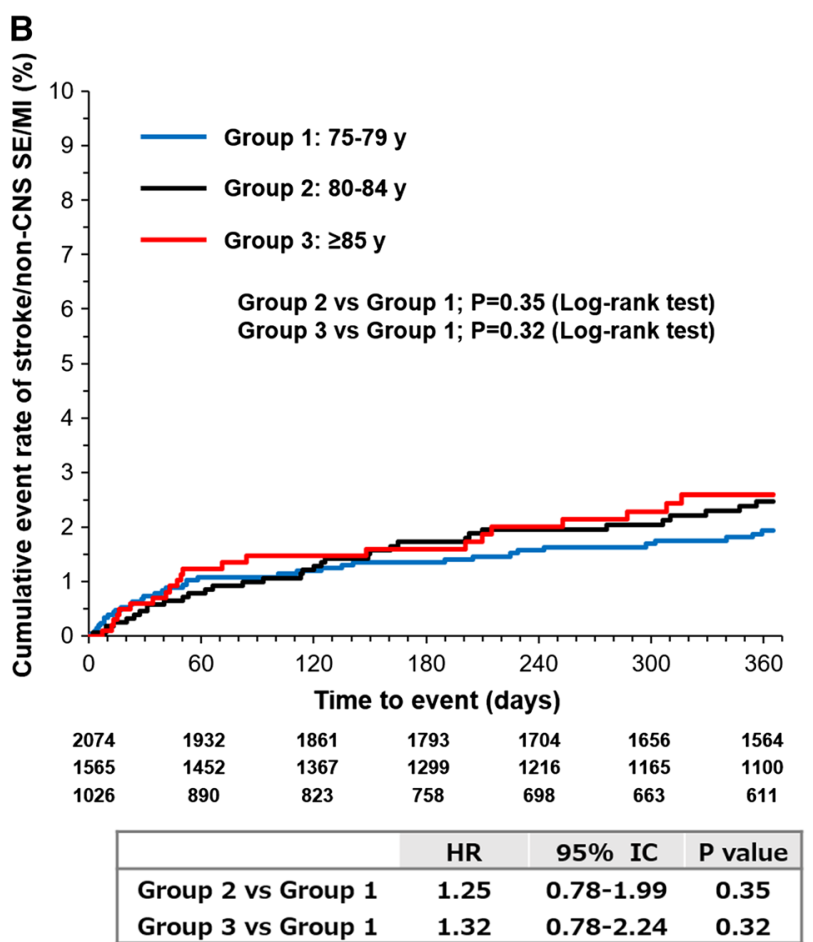

Fig. 2 Kaplan-Meier curves for the cumulative event rate of a major bleeding and b stroke/non-CNS SE/MI among the three elderly patient subgroups (groups $1-3$ : ages $75-79,80-84$, and $\geq 85$ years, respectively) with NVAF

there was no significant increased rates in stroke/non-CNS SE/MI (HR 1.25, 95\% CI 0.78-1.99 for 80-84 years vs. $75-79$ years and HR $1.32,95 \%$ CI $0.78-2.24$ for $\geq 85$ years vs. 75-79 years) (Fig. 2b). A competing risk analysis showed similar results (Supplementary Table 1).

\section{Predictive factors for major bleeding and stroke/ non-CNS SE/MI events}

In multivariable analyses, $\mathrm{CrCl}<50 \mathrm{~mL} / \mathrm{min}$ (HR 1.84 , 95\% CI 1.09-3.12; $P=0.023$ ), hypertension (HR 2.12,
95\% CI 1.01-4.43; $P=0.046$ ), hepatic dysfunction (HR $2.32,95 \%$ CI $1.11-4.85 ; P=0.025)$, and oral antiplatelet use (HR 2.54, 95\% CI 1.25-5.18; $P=0.010$ ) were found to be associated with major bleeding events in patients aged $\geq 75$ years (Table 3 ), while hypertension (HR $0.55,95 \%$ CI $0.31-0.97 ; P=0.038$ ), diabetes mellitus (HR 1.92, 95\% CI 1.10-3.37; $P=0.023$ ), and oral antiplatelet use (HR 2.98, 95\% CI 1.26-7.05; $P=0.013$ ) were identified in patients aged $<75$ years (Supplementary Table 2). Prior ischemic stroke/TIA (HR 1.78, 95\% CI 1.16-2.74; $P=0.009$ ) was associated with stroke/non-CNS SE/MI events in patients 
Table 3 Cox regression analysis for major bleeding and stroke/non-CNS SE/MI in patients aged $\geq 75$ years

\begin{tabular}{|c|c|c|c|c|c|c|c|c|}
\hline \multirow[b]{3}{*}{ Variables } & \multicolumn{4}{|l|}{ Major Bleeding } & \multicolumn{4}{|c|}{ Stroke/non-CNS SE/MI } \\
\hline & \multicolumn{2}{|l|}{ Univariable analysis } & \multicolumn{2}{|c|}{ Multivariable analysis } & \multicolumn{2}{|l|}{ Univariable analysis } & \multicolumn{2}{|c|}{ Multivariable analysis } \\
\hline & $\operatorname{HR}(95 \% \mathrm{CI})$ & $P$ value & HR (95\% CI) & $P$ value & HR $(95 \%$ CI $)$ & $P$ value & $\operatorname{HR}(95 \% \mathrm{CI})$ & $P$ value \\
\hline \multicolumn{9}{|l|}{ Female gender } \\
\hline Yes/no & $1.36(0.89-2.08)$ & 0.156 & $1.34(0.82-2.19)$ & 0.249 & $0.81(0.54-1.22)$ & 0.310 & $0.88(0.55-1.41)$ & 0.597 \\
\hline \multicolumn{9}{|l|}{ Body weight, $\mathrm{kg}$} \\
\hline$>50$ vs. $\leq 50$ & $1.39(0.88-2.19)$ & 0.153 & $1.13(0.66-1.93)$ & 0.669 & $0.91(0.58-1.44)$ & 0.697 & $0.84(0.49-1.44)$ & 0.517 \\
\hline \multicolumn{9}{|l|}{$\mathrm{CrCl}, \mathrm{mL} / \mathrm{min}$} \\
\hline$\geq 50$ vs. $<50$ & $1.76(1.13-2.76)$ & $0.013^{*}$ & $1.84(1.09-3.12)$ & $0.023^{*}$ & $1.31(0.86-1.99)$ & 0.205 & $1.42(0.87-2.31)$ & 0.158 \\
\hline \multicolumn{9}{|l|}{ Initial dose } \\
\hline $10 \mathrm{mg}$ vs. $15 \mathrm{mg}$ & $1.12(0.69-1.82)$ & 0.643 & $0.71(0.41-1.23)$ & 0.225 & $0.94(0.60-1.46)$ & 0.771 & $0.83(0.50-1.39)$ & 0.481 \\
\hline \multicolumn{9}{|l|}{ Hypertension } \\
\hline Yes/no & $1.77(0.94-3.33)$ & 0.077 & $2.12(1.01-4.43)$ & $0.046^{*}$ & $1.47(0.83-2.60)$ & 0.183 & $1.45(0.80-2.64)$ & 0.218 \\
\hline \multicolumn{9}{|l|}{ Diabetes mellitus } \\
\hline Yes/no & $1.39(0.86-2.24)$ & 0.179 & $1.38(0.84-2.27)$ & 0.208 & $0.84(0.50-1.43)$ & 0.530 & $0.78(0.46-1.34)$ & 0.374 \\
\hline \multicolumn{9}{|l|}{$\mathrm{CHF}$} \\
\hline Yes/no & $1.14(0.72-1.80)$ & 0.569 & $1.00(0.61-1.62)$ & 0.992 & $1.19(0.77-1.83)$ & 0.441 & $1.28(0.81-2.00)$ & 0.291 \\
\hline \multicolumn{9}{|c|}{ Prior ischemic stroke/TIA } \\
\hline Yes/no & $1.46(0.93-2.27)$ & 0.097 & $1.38(0.86-2.20)$ & 0.177 & $2.04(1.36-3.08)$ & $<0.001^{*}$ & $1.78(1.16-2.74)$ & $0.009^{*}$ \\
\hline \multicolumn{9}{|l|}{ Vascular disease } \\
\hline Yes/no & $0.91(0.29-2.86)$ & 0.865 & $0.74(0.23-2.39)$ & 0.610 & $1.43(0.58-3.52)$ & 0.435 & $0.95(0.34-2.65)$ & 0.928 \\
\hline \multicolumn{9}{|l|}{ Hepatic dysfunction } \\
\hline yes/no & $2.01(0.97-4.16)$ & 0.060 & $2.32(1.11-4.85)$ & $0.025^{*}$ & $1.11(0.45-2.73)$ & 0.821 & $1.18(0.48-2.92)$ & 0.724 \\
\hline \multicolumn{9}{|l|}{ Oral antiplatelet use } \\
\hline Yes/no & $2.87(1.48-5.55)$ & $0.002^{*}$ & $2.54(1.25-5.18)$ & $0.010^{*}$ & $2.07(1.00-4.28)$ & $0.049^{*}$ & $1.84(0.88-3.86)$ & 0.108 \\
\hline
\end{tabular}

$\mathrm{CHF}$ congestive heart failure, $\mathrm{CI}$ confidence interval, $\mathrm{CrCl}$ creatinine clearance, $\mathrm{HR}$ hazard ratio, $T I A$ transient ischemic attack

$* P<0.05$

aged $\geq 75$ years (Table 3 ), while body weight (HR $2.73,95 \%$ CI 1.23-6.04; $P=0.014$ ), prior ischemic stroke/TIA (HR $2.27,95 \%$ CI $1.24-4.13 ; P=0.008)$, and oral antiplatelet use (HR 4.47, 95\% CI 2.07-9.65; $P<0.001$ ) were identified in patients aged $<75$ years (Supplementary Table 2). Importantly, stepwise regression analysis suggested that $\mathrm{CrCl}<50 \mathrm{~mL} / \mathrm{min}$, hepatic dysfunction, and hypertension were specific predictive factors of major bleeding and no factors were specifically predictive of stroke/non-CNS SE/ MI for patients aged $\geq 75$ years (Supplementary Table 3 ).

\section{Discussion}

This sub-analysis was aimed at evaluating the safety and effectiveness of rivaroxaban treatment for stroke prevention in NVAF patients aged $\geq 75$ years. These patients presented higher rates of both major bleeding and the composite endpoint of stroke/non-CNS SE/MI compared to patients aged $<75$ years. Our results were in agreement with those in the studies of Hori et al. [18] and Lip et al. [1], which showed increased rates of major bleeding and stroke/ thromboembolism rates with advancing age in patients with NVAF. One possible explanation for our results was that impaired kidney function $(\mathrm{CrCl}<50 \mathrm{~mL} / \mathrm{min})$ occurred more frequently in patients aged $\geq 75$ years than in those aged $<75$ years $(41.86 \%$ vs. $6.58 \%$ of patients, respectively). Chronic kidney disease is known to be associated with increased risks of bleeding and stroke in NVAF patients under anticoagulation therapy [19]. Another possible reason was the higher prevalence of cardiovascular conditions with consequent higher risk scores, such as $\mathrm{CHADS}_{2}$, $\mathrm{CHA}_{2} \mathrm{DS}_{2}$-VASc, and modified HAS-BLED, in patients aged $\geq 75$ years. Of note, there was no significant difference in the $\mathrm{ICH}$ rate between the two age groups treated with rivaroxaban. In both groups, the $\mathrm{ICH}$ rate was $<1$ event per 100 patient-years, which was consistent with the pivotal studies of ROCKET AF [4] and J-ROCKET AF [5]. A possible explanation for the similar $\mathrm{ICH}$ rate between the two age groups in our sub-analysis could be partially explained by physicians' careful management of comorbidities and concomitant medications. We speculate that modifiable bleeding risk factors, such as blood pressure, invasive procedures, and concomitant medications, were appropriately 
controlled especially in patients aged $\geq 75$ years. The Shikoku Rivaroxaban Registry Trial in Japanese real-world settings reported similarly that there was no significant difference in the ICH rate between extremely elderly patients ( $\geq 80$ years) and control patients ( $<80$ years) [20]. Further study will be needed to examine the relationship between age and ICH rate in patients taking DOACs.

An interesting finding was that there was no significant difference in major bleeding or stroke/non-CNS SE/MI events among the 3 elderly sub-populations (age ranges: 75-79, 80-84, and $\geq 85$ years). Since the target population was very old and the mortality rate of this population was higher than the thromboembolic and major bleeding rates particularly for patients over 80 years old (Supplementary Fig. 1), we performed the competing risk analysis to evaluate the impact of death. The comparison of hazard ratios obtained with Cox regression and the competing risk analysis suggested that the impact of mortality on major bleeding and stroke/non-CNS SE/MI outcomes was negligible (Supplementary Table 1). Emerging evidences indicate that ignoring the competing death risk can lead to biased estimates of stroke risks especially in elderly AF patients $[21,22]$; however, this was not the case in this analysis. One possible reason could be a shorter follow-up period (1 year), which might have limited the effect of death rate. Follow-up data collected over a longer period analyzed with the competing risk method will be required to access the impact of the observation period. Despite the limitation mentioned above, our findings may be attributed in part to the "healthy survivor effect" [23], meaning that one would be sufficiently healthy to be alive. We presume the elderly sub-populations were healthy enough and, as a result, their thromboprophylaxis outcomes did not differ significantly among the sub-populations. Indeed, no higher prevalence of comorbidities was found among the subpopulations, even though the mean $\mathrm{CrCl}$ values were sharply decreased with increasing age (Supplementary Table 4). Also, advancing chronological age is not always directly linked to poor health, which suggests that the chronological age number should not be the only factor used as a health index. Furthermore, careful risk-benefit assessment or management of patients by the physicians may give better results across all the elderly sub-populations. However, the results of the XAPASS study should be interpreted carefully, since bias may have been introduced into the outcome data, which is one of the limitations of post-marketing surveillance studies.

Currently, the elderly population continues to age and a longer life expectancy has become increasingly common in certain countries [24]. Japan has already entered into the era of a super-aged society. As an example, in the 1-year results of the XAPASS, the average age was $73.2 \pm 9.8$ [12], and our result showed that almost half of the 9,578 patients with NVAF were aged $\geq 75$ years. The average age was similar to that found in various registries throughout Japan, including the EXPAND, SAKURA AF, RAFFINE, and Fushimi AF registries [25-28]. This impressive demographic aging is related to an undeniable social and economic burden, and a balanced approach in elderly medical care settings is imperative for the sustainability of the healthcare system [1]. Several lines of evidence indicate that DOACs are cost effective compared to warfarin, yet it is still controversial whether lines of evidence apply to elderly patients ( $\geq 75$ years) in real-world settings since they have increased bleeding risks compared to younger elderly patients (65-74 years) [29]. Therefore, decisions on appropriate AF treatment should ultimately be individualized and should balance treatmentrelated benefits, risks, cost, and patient preferences.

The use of anticoagulation requires risk-benefit assessment, especially for elderly patients with AF. First, even though bleeding concern is a serious issue, there are several findings which support the use of oral anticoagulants (OACs) in elderly for the prevention of thromboembolic complications of AF, such as, the recently published PREFER in AF Registry conducted in European countries [30]. The incidence rate of thromboembolic events, which includes stroke/TIA/systemic embolism, was higher in the very elderly ( $\geq 85$ years) than in younger ( $<85$ years) AF patients, and the use of OACs resulted in a greater absolute reduction in the incidence rate in elderly ( $\geq 85$ years) than in younger $(<85$ years) AF patients ( $2 \%$ vs. $0.5 \%$ ). In elderly patients ( $\geq 85$ years), the risk of major bleeding was higher than in younger ( $<85$ years) patients, but similar in patients on OACs and in those on antiplatelet therapy or without antithrombotic treatment. Second, Chao TF et al. showed that very elderly patients with $\mathrm{AF}$ ( $\geq 90$ years) still benefit from DOACs treatment [31]. DOACs may be considered for stroke prevention in this extreme aged population, given the significant stroke risk reduction and the positive net clinical benefit. Also, DOACs were associated with a lower risk of ICH compared with warfarin. Third, in a sub-analysis of the ROCKET AF trial, rivaroxaban was found to have a higher net clinical benefit than warfarin in elderly patients [32], although it remains to be determined whether this is true in real-world Japanese clinical practice. We assume advanced age continues to be an important barrier to anticoagulation treatment as in the past [33], where stroke risk was underestimated and bleeding, lack of adherence, and falls risk are overestimated; however, such a recognition may become antiquated.

Careful risk assessment at the start of OACs is crucial to prevent adverse events in high risk elderly patients. Importantly, minimizing any modifiable risk factors such as uncontrolled hypertension, concurrent antiplatelet agent use, nonsteroidal anti-inflammatory drug use, and harmful alcohol consumption may decrease bleeding in such patients during protection against stroke using DOACs [34]. Additionally, close monitoring is necessary in elderly patients as their health condition could rapidly deteriorate. We investigated the predictive factors of major bleeding and stroke/non-CNS SE/MI events for the elderly patients. In our Cox regression 
analyses, $\mathrm{CrCl}<50 \mathrm{~mL} / \mathrm{min}$ and hepatic dysfunction were indicated as specific predictive factors for major bleeding in patients aged $\geq 75$ years, while no specific predictive factor of stroke/non-CNS SE/MI was identified. Even though renal dysfunction and hepatic dysfunction are not necessarily medically manageable factors, this information may help physicians manage bleeding more effectively in such patients. We included hypertension as a specific predictive factor of major bleeding for patients aged $\geq 75$ years, as it was negatively associated with major bleeding events in patients aged $<75$ years. On the other hand, prior ischemic stroke/TIA in stroke/non-CNS SE/MI and oral antiplatelet use in major bleeding were identified for both patients aged $\geq 75$ and $<75$ years. A similar tendency was observed in a sub-analysis of the EXPAND study, which investigated risk factors for stroke/systemic embolism and major bleeding in Japanese NVAF patients receiving rivaroxaban [35].

There are some limitations of this sub-analysis. First, the XAPASS is a single-arm study. It is impossible to directly compare the outcomes of rivaroxaban treatment with those of other treatments such as warfarin and other DOACs, as previously described [12]. Second, the sub-analysis was an only 1-year follow-up, limiting the ability to assess for late clinical events. Third, the loss of patients to follow-up might have also led to an underestimation of the event rates. Fourth, there might be some potential selection bias by the physicians.

In conclusion, a specific caution should be implemented when it comes to the treatment of elderly patients with NVAF. However, we understand with the aging of the world population, elderly patients should not be left untreated. The previous concept of not offering an available and indicated therapy simply because of "old age" may need to be revisited. Individualized analysis of the medical history and meticulous risk assessment should be considered in the decision making to decrease risk and increase the quality of life benefits for this unique population.

Acknowledgements Writing assistance was provided by Michelle L. Jones, PhD, ELS, and publication support was provided by McCann MDS, Inc.

Funding This study was funded by Bayer Yakuhin Ltd. (Osaka, Japan).

\section{Compliance with ethical standards}

Conflict of interest The author TK was advisory board member for Bayer Yakuhin Ltd. (Bayer) and received research grant from the same. TI received research grant from Daiichi Sankyo (Daiichi), Bristol-Myers Squibb (BMS), Medtronic Japan, St. Jude Medical, Bayer; honoraria from Daiichi, Ono Pharma, Pfizer, Bayer, BMS and was member of advisory board for the last two companies. SO was advisory board member ( $\mathrm{AB}$ ) for Bayer. JN received research grant from Nihon MediPhysics and $\mathrm{AB}$ member for Bayer. KM received honoraria from Bayer, Otsuka Pharma, Boehringer Ingelheim (BI), AstraZeneca, Pfizer, Mitsubishi Tanabe, Stryker, Kowa, Nihon Medi-Physics Co, BMS, Sawai Pharma, Sumitomo Dainippon Pharma, Daiichi, Astellas, Nippon
Chemiphar and was member of AB for CSL Behring, Medico's Hirata, Bayer. SM received research grant from Takeda Pharma, CSL Behring, Meiji Seika Pharma, MSD, Astellas, Eisai, Otsuka Pharma, Carl Zeiss Meditec, Philips Electronics Japan, Sanofi, Siemens Healthcare, Daiichi, Mitsubishi Tanabe, Chugai Pharma, Nihon Medi-Physics, Pfizer, BMS, Brainlab, Mizuho, and Medtronic and was AB member for Bayer. YM received research grant from Bayer, Daiichi, BI; honoraria from Bayer, Daiichi, BI, BMS and was AB member for Bayer. MC, YH, YK, YO, TS, SS, SY are employees of Bayer Yakuhin Ltd.

Open Access This article is distributed under the terms of the Creative Commons Attribution 4.0 International License (http://creativeco mmons.org/licenses/by/4.0/), which permits unrestricted use, distribution, and reproduction in any medium, provided you give appropriate credit to the original author(s) and the source, provide a link to the Creative Commons license, and indicate if changes were made.

\section{References}

1. Lip GY, Clementy N, Pericart L, Banerjee A, Fauchier L (2015) Stroke and major bleeding risk in elderly patients aged $\geq 75$ years with atrial fibrillation: the Loire Valley atrial fibrillation project. Stroke 46(1): 143-150

2. Abumuaileq RRY (2019) Risk of major bleeding in very elderly patients with atrial fibrillation-a continuous dilemma in the real world clinics. Evid Perspect Angiol 7(1):e119

3. Shoeb M, Fang MC (2013) Assessing bleeding risk in patients taking anticoagulants. J Thromb Thrombolysis 35(3):312-319

4. Patel MR, Mahaffey KW, Garg J, Pan G, Singer DE, Hacke W, Breithardt G, Halperin JL, Hankey GJ, Piccini JP, Becker RC, Nessel CC, Paolini JF, Berkowitz SD, Fox KAA, Califf RM, ROCKETAF Investigators (2011) Rivaroxaban versus warfarin in nonvalvular atrial fibrillation. N Engl J Med 365(10):883-891

5. Hori M, Matsumoto M, Tanahashi N, Momomura S, Uchiyama S, Goto S, Izumi T, Koretsune Y, Kajikawa M, Kato M, Ueda H, Iwamoto K, Tajiri M, J-ROCKET AF Study Investigators (2012) Rivaroxaban vs. warfarin in Japanese patients with atrial fibrillation: the J-ROCKET AF study. Circ J 76(9), 2104-2111.

6. Suvarna VR (2018) Real world evidence (RWE) — are we (RWE) ready? Perspect Clin Res 9(2):61-63

7. Arai H, Ouchi Y, Toba K, Endo T, Shimokado K, Tsubota K, Matsuo S, Mori H, Yumura W, Yokode M, Rakugi H, Ohshima S (2015) Japan as the front-runner of super-aged societies: perspectives from medicine and medical care in Japan. Geriatr Gerontol Int 15(6):673-687

8. Global Health Observatory Data Repository: life expectancydata by country (CSV). Geneva: World Health Statistics; 2015. https://apps.who.int/gho/data/node.main.688?lang=en. Accessed 20 July 2015

9. Boriani G (2016) Atrial fibrillation and aging: risky mutual relationships. Chest 149(2):301-302

10. Inoue H, Fujiki A, Origasa H, Ogawa S, Okumura K, Kubota I, Aizawa Y, Yamashita T, Atarashi H, Horie M, Ohe T, Doi Y, Shimizu A, Chishaki A, Saikawa T, Yano K, Kitabatake A, Mitamura H, Kodama I, Kamakura S (2009) Prevalence of atrial fibrillation in the general population of Japan: an analysis based on periodic health examination. Int J Cardiol 137(2):102-107

11. Ogawa S, Minematsu K, Ikeda T, Kitazono T, Nakagawara J, Miyamoto S, Murakawa Y, Ohashi Y, Takeichi M, Okayama Y, Yamanaka S, Inuyama L (2018) Design and baseline characteristics of the Xarelto post-authorization safety \& effectiveness study 
in Japanese patients with atrial fibrillation (XAPASS). J Arrhythm 34(2):167-175

12. Ikeda T, Ogawa S, Kitazono T, Nakagawara J, Minematsu K, Miyamoto S, Murakawa Y, Takeichi M, Ohashi Y, Okayama Y, Sunaya T, Yamanaka S (2019) Real-world outcomes of the Xarelto postauthorization safety \& effectiveness study in Japanese patients with atrial fibrillation (XAPASS). J Cardiol 74(1):60-66

13. Gage BF, Waterman AD, Shannon W, Boechler M, Rich MW, Radford MJ (2001) Validation of clinical classification schemes for predicting stroke: results from the National Registry of Atrial Fibrillation. JAMA 285(22):2864-2870

14. Lip GY, Nieuwlaat R, Pisters R, Lane DA, Crijns HJ (2010) Refining clinical risk stratification for predicting stroke and thromboembolism in atrial fibrillation using a novel risk factorbased approach: the euro heart survey on atrial fibrillation. Chest 137(2):263-272

15. Pisters R, Lane DA, Nieuwlaat R, de Vos CB, Crijns HJ, Lip GY (2010) A novel user-friendly score (HAS-BLED) to assess 1-year risk of major bleeding in patients with atrial fibrillation: the Euro Heart Survey. Chest 138(5):1093-1100

16. Schulman S, Kearon C, Subcommittee on Control of Anticoagulation of the Scientific, and Standardization Committee of the International Society on Thrombosis, and Haemostasis (2005) Definition of major bleeding in clinical investigators of antihemostatic medicinal products in non-surgical patients. J Thromb Haemost 3(4):692-694

17. Fine JP, Gray RJ (1999) A proportional hazards model for the subdistribution of a competing risk. J Am Stat Assoc 94(446):496-509

18. Hori M, Matsumoto M, Tanahashi N, Momomura S, Uchiyama S, Goto S, Izumi T, Koretsune Y, Kajikawa M, Kato M, Ueda H, Iekushi K, Yamanaka S, Tajiri M, J-ROCKET AF Study Investigators (2014) Rivaroxaban vs. warfarin in Japanese patients with nonvalvular atrial fibrillation in relation to age. Cir J 78(6), 1349-1356.

19. Olesen JB, Lip GY, Kamper AL, Hommel K, Køber L, Lane DA, Lindhardsen J, Gislason GH, Torp-Pedersen C (2012) Stroke and bleeding in atrial fibrillation with chronic kidney disease. N Engl J Med 367(7):625-635

20. Bando S, Nishikado A, Hiura N, Ikeda S, Kakutani A, Yamamoto K, Kaname N, Fukatani M, Takagi Y, Yukiri K, Fukuda Y, Nakaya Y (2018) Efficacy and safety of rivaroxaban in extreme elderly patients with atrial fibrillation: analysis of the Shikoku Rivaroxaban Registry Trial (SRRT). J Cardiol 71(2):197-201

21. Ashburner JM, Go AS, Chang Y, Fang MC, Fredman L, Applebaum KM, Singer DE (2017) Influence of competing risks on estimating the expected benefit of warfarin in individuals with atrial fibrillation not currently taking anticoagulants: the anticoagulation and risk factors in atrial fibrillation study. $\mathrm{J}$ Am Geriatr Soc 65(1):35-41

22. Abdel-Qadir H, Fang J, Lee DS, Tu JV, Amir E, Austin PC, Anderson GM (2018) Importance of considering competing risks in time-to-event analyses: application to stroke risk in a retrospective cohort study of elderly patients with atrial fibrillation. Circ Cardiovasc Qual Outcomes 11(7):e004580

23. Murphy TE, Han L, Allore HG, Peduzzi PN, Gill TM, Lin H (2011) Treatment of death in the analysis of longitudinal studies of gerontological outcomes. J Gerontol A Biol Sci Med Sci 66(1):109-114

24. United Nations DoEaSA, Population Division (2017) World population prospects: the 2017 revision, key findings and advance tables. Working Paper No ESA/P/WP/248

25. Shimokawa H, Yamashita T, Uchiyama S, Kitazono T, Shimizu W, Ikeda T, Kamouchi M, Kaikita K, Fukuda K, Origasa H, Sakuma I, Saku K, Okumura Y, Nakamura Y, Morimoto H, Matsumoto N,
Tsuchida A, Ako J, Sugishita N, Shimizu S, Atarashi H, Inoue H (2018) The EXPAND study: efficacy and safety of rivaroxaban in Japanese patients with non-valvular atrial fibrillation. Int J Cardiol 258:126-132

26. Okumura Y, Yokoyama K, Matsumoto N, Tachibana E, Kuronuma K, Oiwa K, Matsumoto M, Kojima T, Hanada S, Nomoto K, Arima K, Takahashi F, Kotani T, Ikeya Y, Fukushima S, Itoh S, Kondo K, Chiku M, Ohno Y, Onikura M, Hirayama A, The Sakura Af Registry Investigators (2017) Current use of direct oral anticoagulants for atrial fibrillation in Japan: findings from the SAKURA AF Registry. J Arrhythm 33(4):289-296

27. Miyazaki S, Miyauchi K, Hayashi H, Tanaka R, Nojiri S, Miyazaki T, Sumiyoshi M, Suwa S, Nakazato Y, Urabe T, Hattori N, Daida H (2018) Registry of Japanese patients with atrial fibrillation focused on anticoagulant therapy in the new era: the RAFFINE registry study design and baseline characteristics. J Cardiol 71(6):590-596

28. Akao M, Chun YH, Wada H, Esato M, Hashimoto T, Abe M, Hasegawa K, Tsuji H, Furuke K, Fushimi AF Registry Investigators (2013) Current status of clinical background of patients with atrial fibrillation in a community-based survey: the Fushimi AF Registry. J Cardiol 61(4):260-266

29. Zhao YJ, Lin L, Zhou HJ, Tan KT, Chew AP, Foo CG, Oh CT, Lim BP, Lim WS (2016) Cost-effectiveness modelling of novel oral anticoagulants incorporating real-world elderly patients with atrial fibrillation. Int J Cardiol 220:794-801

30. Patti G, Lucerna M, Pecen L, Siller-Matula JM, Cavallari I, Kirchhof P, De Caterina R (2017) Thromboembolic risk, bleeding outcomes and effect of different antithrombotic strategies in very elderly patients with atrial fibrillation: a sub-analysis from the PREFER in AF (PREvention oF Thromboembolic EventsEuropean Registry in Atrial Fibrillation). J Am Heart Assoc 6(7): 0005657

31. Chao TF, Liu CJ, Lin YJ, Chang SL, Lo LW, Hu YF, Tuan TC, Liao JN, Chung FP, Chen TJ, Lip GYH, Chen SA (2018) Oral anticoagulation in very elderly patients with atrial fibrillation: a nationwide cohort study. Circulation 138(1):37-47

32. Halperin JL, Hankey GJ, Wojdyla DM, Piccini JP, Lokhnygina Y, Patel MR, Breithardt G, Singer DE, Becker RC, Hacke W, Paolini JF, Nessel CC, Mahaffey KW, Califf RM, Fox KA, ROCKETAF Steering Committee Investigators (2014) Efficacy and safety of rivaroxaban compared with warfarin among elderly patients with nonvalvular atrial fibrillation in the rivaroxaban once daily, oral, direct factor Xa inhibition compared with vitamin $\mathrm{K}$ antagonism for prevention of stroke and embolism trial in atrial fibrillation (ROCKET AF). Circulation 130(2):138-146

33. Pugh D, Pugh J, Mead GE (2011) Attitudes of physicians regarding anticoagulation for atrial fibrillation: a systematic review. Age Ageing 40(6):675-683

34. Habert JS (2016) Minimizing bleeding risk in patients receiving direct oral anticoagulants for stroke prevention. Int J Gen Med 9:337-347

35. Sakuma I, Uchiyama S, Atarashi H, Inoue H, Kitazono T, Yamashita T, Shimizu W, Ikeda T, Kamouchi M, Kaikita K, Origasa H, Shimokawa H (2019) Clinical risk factors of stroke and major bleeding in patients with non-valvular atrial fibrillation under rivaroxaban: the EXPAND Study sub-analysis. Heart Vessels. https://doi.org/10.1007/s00380-019-01425-x

Publisher's Note Springer Nature remains neutral with regard to jurisdictional claims in published maps and institutional affiliations. 


\section{Affiliations}

\section{Takanari Kitazono ${ }^{1} \cdot$ Takanori Ikeda $^{2}$ - Satoshi Ogawa ${ }^{3} \cdot$ Jyoji Nakagawara ${ }^{4,5} \cdot$ Kazuo Minematsu $^{5,6}$.} Susumu Miyamoto ${ }^{7}$ - Yuji Murakawa ${ }^{8} \cdot$ Mary Cavaliere $^{9} \cdot$ Yasuhiro Hayashi $^{9} \cdot$ Yoko Kidani $^{9} \cdot$ Yutaka Okayama $^{10}$. Toshiyuki Sunaya $^{11}$. Shoichiro Sato ${ }^{10} \cdot$ Satoshi Yamanaka ${ }^{9}$

1 Department of Medicine and Clinical Science, Graduate School of Medical Sciences, Kyushu University, 3-1-1 Maidashi, Higashi-ku, Fukuoka 812-8582, Japan

2 Department of Cardiovascular Medicine, Toho University Graduate School of Medicine, Tokyo, Japan

3 International University of Health and Welfare Mita Hospital, Tokyo, Japan

4 Osaka Namba Clinic, Osaka, Japan

5 National Cerebral and Cardiovascular Center, Suita, Osaka, Japan

6 Iseikai Medical Corporation, Osaka, Japan
7 Department of Neurosurgery, Kyoto University Graduate School of Medicine, Kyoto, Japan

8 The 4th Department of Internal Medicine, Teikyo University School of Medicine, Mizonokuchi Hospital, Kawasaki, Japan

9 Medical Affairs Thrombosis, Medical Affairs, Bayer Yakuhin, Ltd., Osaka, Japan

10 Pharmacovigilance Monitoring and Medical Governance, Medical Affairs, Bayer Yakuhin, Ltd., Osaka, Japan

11 Research and Development Japan/Data Sciences and Analytics/Statistics and Data Insights, Bayer Yakuhin, Ltd., Osaka, Japan 